\title{
DOCUMENTOS
}

\section{Mesa de conversación: "La enseñanza de la composición en Chile", en el marco del Festival Pedro Humberto Allende y el Encuentro Nacional de Compositores (ANC)}

\author{
editado por \\ Daniela Fugellie Videla \\ Instituto de Música, Universidad Alberto Hurtado, Chile \\ dfugellie@uahurtado.cl \\ Gabriel Matthey Correa \\ Facultad de Artes, Universidad de Chile, Chile \\ gmattheyc@hotmail.com
}

\section{CONTEXTUALIZACIÓN DEL ENCUENTRO}

Antes de presentar los contenidos de la mesa de conversación, es admisible señalar que desde que se empezó a organizar el Festival Pedro Humberto Allende, siempre se consideró incluir un espacio de intercambio en torno a la formación actual de los compositores chilenos, por cuanto calzaba muy bien con el espíritu que inspiraba al Festival. Además, era una buena oportunidad para hacerlo, debido a la escasa frecuencia con que se realiza este tipo de conversaciones entre compositores y, menos, respecto de la enseñanza. De hecho, una mesa de carácter similar se realizó en 1996, en torno al trabajo y legado musical que dejó Fré Focke en Chile. En esa ocasión, sin embargo, el énfasis se puso en la inserción y repercusión que tuvo el serialismo dodecafónico en el lenguaje de un grupo importante de compositores chilenos ${ }^{1}$.

Poco después, pero ese mismo año, tuve la oportunidad de conversar con Gustavo Becerra, en una de sus últimas visitas a Chile. Recuerdo que compartimos un café en "El Flora", fuente de soda o restaurante que reunía a músicos, el que se ubicaba a media cuadra de la Facultad de Artes de la Universidad de Chile, en calle Teatinos. Entonces Gustavo me dijo algo muy significativo: "No hay duda que con la presencia de Cirilo Vila se instaló un nuevo piso en la música chilena”". En efecto, dicho comentario daba cuenta de un punto de inflexión en la formación de compositores chilenos, gracias a las clases de Cirilo, principalmente de análisis, armonía, lectura de partituras y, por cierto, de composición.

1 Ver Revista Musical Chilena LI/187 (1997), pp. 42-62.

2 Y esto no solo se refiere a la música contemporánea de tradición escrita, sino además a la música popular, ámbito en que Cirilo Vila también tuvo cierta incidencia. Incluso aportó en música para cine mudo, donde él, en exhibiciones ocasionales, improvisaba en el piano. 
Veintiún años después, la mesa de conversación realizada el 6 de septiembre de 2017 nos dio la oportunidad de escuchar el enfoque de cuatro compositores chilenos que actualmente imparten clases de composición, todos con una vasta experiencia al respecto, lo que ahora nos permite tener una mirada actualizada de la enseñanza de la composición musical en nuestro país. A continuación, entonces, se incluyen los contenidos de dicha conversación, que sin duda nos entrega nuevas luces al respecto.

Mesa de conversación: "La enseñanza de la composición en Chile", en el marco del "Festival Pedro Humberto Allende y el Encuentro Nacional de Compositores (ANC)". Miércoles 6 de septiembre de 2017, 18.30 horas, Sala Alonso de Ercilla, Biblioteca Nacional

\section{Compositores participantes:}

Antonio Carvallo Pinto, presidente de la Asociación Nacional de Compositores-Chile, a cargo de la introducción.

Gabriel Matthey Correa (GM), a cargo de la coordinación y moderación de la mesa.

Compositores invitados a la mesa: Pablo Aranda Rojas (PA), Eduardo Cáceres Romero (EC), Alejandro Guarello Finlay (AG) y Aliocha Solovera Roje (AS) ${ }^{3}$.

\section{REPRODUCGIÓN DE LA MESA DE CONVERSACIÓN ${ }^{4}$}

Antonio Carvallo: Buenas tardes. En el marco de la organización del "Festival Pedro Humberto Allende", conversando con el profesor Luis Merino y con Gabriel Matthey, surgió la idea, como parte del Festival, de sentarnos a conversar acerca de la enseñanza de la composición en Chile. Hay ciertos elementos de la enseñanza que suelen darse, a veces, por descontados, por ejemplo la estrecha relación entre el alumno y el profesor. La verdad es que esto nos invita a entrar en diferentes ángulos respecto de la relación entre ambos: ¿qué pasa ahí?, ¿cómo es realmente el proceso de enseñar y aprender la composición?, ¿cuáles son las distintas metodologías de los diferentes profesores?

Como les decía, pareciera ser que hay varias cosas que se dan por descontadas, pero también parecieran haber muchos secretos o cosas por observar. En ese sentido, creemos que compartir con destacados invitados como los aquí presentes, los maestros Alejandro Guarello, Aliocha Solovera, Pablo Aranda y Eduardo Cáceres, junto con Gabriel Matthey como moderador, nos permitirá establecer una mesa de conversación abierta, que creo será bastante interesante y productiva para todos los que estamos relacionados con el mundo de la composición y, específicamente, de su enseñanza. Esta instancia surgió y se organiza a partir de la Asociación Nacional de Compositores - de hecho todos los presentes en la mesa son miembros de nuestra Asociación-y les doy la más cordial bienvenida. A continuación, entonces, le cedo la palabra a Gabriel, para que inicie la mesa.

GM: Gracias Antonio. ¡Buenas tardes a todas las personas presentes!... En realidad estamos en un momento bien especial, pues recientemente expuso acá Juan Allende-Blin, a quien fue muy interesante escuchar por su propia experiencia en cuanto a la formación de compositores. Fue sorprendente, ya que su metodología en gran medida coincide con el proceso de formación que muchos de nosotros hemos tenido acá en Chile. Además, sorprende escucharlo especialmente a él, que ya tiene casi noventa años. Asimismo, es muy interesante ver aquí en la sala a mucha gente joven, por cuanto creo que así estamos logrando un vínculo importante entre distintas generaciones.

Agradezco a los colegas compositores que aceptaron participar en la mesa. Les confieso que cuando tuvimos que decidir a quiénes invitar surgieron varios nombres. Sin embargo, estimamos que los aquí presentes son representantes de quienes llevan más tiempo enseñando composición acá en

3 También fue invitado el compositor Andrés Alcalde, quien se excusó de asistir por razones personales.

4 Transcripción a cargo de Sergio Araya, revisada por Daniela Fugellie, en el marco del proyecto Fondecyt Iniciación 11170844, "Espacios alternativos de la música contemporánea en Chile (19451995)". Agradecemos a Cecilia Astudillo, directora del Archivo de Música de la Biblioteca Nacional de Chile, por haber proporcionado este material audiovisual para su transcripción y a los compositores participantes por acceder a su publicación. 
Santiago, para ser más precisos. Claro, porque si bien la mesa se llama "La enseñanza de la composición en Chile", la verdad es que en rigor tenemos que decir "en Santiago", porque en regiones también ya están existiendo escuelas de composición, cuyas voces y experiencias igualmente sería interesante escuchar. Digo esto pues recuerdo que, hace ya más de veinte años, cuando vino Pierre Boulez a Chile (1996), época en que aún no había internet, me correspondió personalmente convocar a un encuentro con él en la Sala Arrau del Teatro Municipal. Entonces vino gente desde Arica a Punta Arenas. Sin embargo, ahora es diferente, pues creo que los asistentes son solo de Santiago. Igual me comuniqué con las regiones para invitar a posibles interesados en asistir a esta mesa, pero noté un cambio radical: actualmente cada región tiene sus propios proyectos; cada región está haciendo sus cosas; cada región se conecta con el mundo por su cuenta. Ya no es como antes, cuando las regiones tenían que "pasar por Santiago" para poder conectarse con el mundo. Esto demuestra que nuestra realidad ha ido cambiando en forma importante.

Ahora bien, respecto de la mesa que hoy nos convoca, además les quiero contar que hace mucho tiempo que no realizábamos una actividad así. Deben ser más de veinte años que se hizo una mesa de conversación en torno a la música de Fré Focke y sus discípulos, donde también participaron varios compositores. Es demasiado tiempo, lo que demuestra cómo nos cuesta encontrarnos y comunicarnos; cómo nos cuesta conversar acerca de temas que a todos nos importan. Por ello hoy, la presencia de ustedes, profesores de composición, es muy importante y se les agradece desde ya... Lo propio vale para el público presente.

Y bien, para iniciar entonces la mesa, antes de hablar de la educación y formación del compositor, creo que primero sería bueno proceder a que cada uno de ustedes brevemente nos cuente, por favor, con quiénes se formaron y qué destacan de su experiencia en su propio proceso de formación; qué les quedó fundamentalmente de lo que aprendieron de sus propios maestros... Se les ofrece la palabra.

AG: Buenas tardes. Yo me formé con dos profesores emblemáticos, diría yo, que tienen que ver con la composición, incluso en el caso de doña Lucila Césped, que enseñaba en su casa, en calle Libertad 132, segundo piso. Ella era mi profesora de armonía, contrapunto, análisis, etc., y yo empecé a componer con ella. Me hacía ejercicios de composición, pero llegó un momento en que se enfermó de la vista y me derivó a Cirilo Vila, con el que estudié en forma privada por dos años, hasta que me obligó a entrar a la institución, a la Universidad de Chile. Yo no quería, pero él me obligó. Y se lo agradezco, porque en realidad el sistema cambió a nivel mundial y hoy el que no tiene un título o un cartón no vale nada, aunque sea un genio, un gran compositor. Incluso después, y hasta hoy, si no se tenía un título, ya no se podía enseñar ni siquiera en los colegios, lo que no es menor.

Y Cirilo, con su tranquilidad y sabiduría características, tenía una virtud que yo empecé a notar rápidamente, y era que por medio de la música, toda la música, él enseñaba a componer y, principalmente, enseñaba a tomar decisiones. Él no corregía, por lo menos a mí, en el sentido de "mira, esto está mal, esto se hace así”. Él simplemente mostraba, nada más, y me decía: "Aquí, mira, piensa... Revisa, piensa”. No daba soluciones. Sin más, se conversaba de los problemas en términos genéricos. Y los ejemplos, evidentemente, eran de su mundo musical, que no necesariamente era el mundo de la música contemporánea. Eso es muy interesante, porque nosotros entre el 77 y el 81, que estuve en la Facultad, en general las ocasiones que uno tenía contacto con la música contemporánea eran pocas... habían unas "partituras locas" por ahí; había poco menos que rogar a alguien para que te prestara las partituras de Berio... Y así entonces, con mayor razón, la experiencia con Cirilo era notable, porque él enseñaba a pensar y a resolver problemas que eran similares a los que tenían Guillaume de Machaut, Palestrina, Mozart, Beethoven, Stravinsky, Debussy... y uno veía cómo la problemática seguía siendo la misma. Cambiaba la estética, obviamente, pero el pensamiento y la lógica del discurso musical era una cosa que se aprendía ahí con él. Creo que con eso basta por el momento, y quiero aprovechar de agradecer [a Cirilo]. Claro, él ya no está con nosotros, pero siempre le tendré una gratitud eterna porque efectivamente era un músico cabal, de pies a cabeza, de codo a codo, por todos lados, por dentro, por fuera. Era maravilloso y fue una gran suerte poder estudiar con él.

Posteriormente continué estudiando gracias, justamente, a la obligación que me puso Cirilo, de hacerme entrar a la institución. Entonces obtuve una beca para irme a Italia y estudié con Franco Donatoni y Giacomo Manzoni, en un mundo que era aparentemente muy distinto. Sin embargo, los problemas composicionales eran los mismos. La manera de enfrentarlos y el mundo estético que les correspondía, era distinto, por cierto, pero yo no establecería demasiadas diferencias fundamentales en relación con el sistema de enseñanza. La parte estética sí, porque obviamente sus músicas son muy 
diferentes. O sea, comparar In Memoriam a Bartók de Cirilo con una obra de Donatoni o con una obra de Manzoni, son absolutamente distintas. Sin embargo, en los tres profesores me tocó sentir y ver una misma actitud: una forma de hacer y pensar la música. No era una cuestión técnica, sino un hablar acerca de un problema composicional y a uno lo dejaban libre para decidir según lo que supuestamente tenía que encontrar como solución, para bien o para mal. Eso es un poco lo que les puedo contar, por el momento, respecto de la experiencia de mi propia formación.

AS: Mi caso es bien especial, porque yo nací en Chile pero a los ocho años me fui a vivir a Croacia, porque mi mamá es croata, nacida en Croacia, y ahí empecé mis estudios de música. Primero estudié violín, pero no me fue muy bien; después me cambié a flauta traversa, donde llegué hasta el nivel medio. Y estando en el nivel medio, que en Croacia es entre los 14 y 18 años, ya tenía clases de contrapunto y armonía (acá en Chile eso generalmente se da solo a nivel superior). Entonces empecé a descubrir que, la verdad, me interesaba mucho componer, aunque todavía no me atrevía a asumirlo... Empecé estudiando teoría musical en Ljubljana, Eslovenia, donde uno de los profesores -como decía Alejandrome obligó a estudiar composición. Y sobre la base de mis trabajos de composición en estilo, que a este profesor le parecieron muy buenos, él habló con otro profesor, que era el más conocido en Eslovenia, Alojz Srebotnjak, y arregló todo para que finalmente yo pudiera entrar a estudiar composición. Creo que Alojz Srebotnjak fue mi único profesor importante. Tuve otros profesores, claro, pero él era un profesor muy dedicado, que miraba cada detalle, era muy minucioso y yo creo que él me marcó de todas maneras. También me marcó el ambiente propio de Eslovenia, porque probablemente ustedes saben que en Europa del Este había, se podría decir, un lenguaje más conservador; un lenguaje más neoclásico que era lo que predominaba. La razón se debía a muchas cosas, pues, entre otras, en esa época todavía era Yugoslavia y, en cuanto a música, yo creo que había menos partituras allá que acá en Chile, siendo que estábamos al lado de países donde había de todo.

Terminé mis estudios en Ljubljana y me fue bastante bien en el medio esloveno. Creo que en eso fue de mucha ayuda el apoyo de un gran director de orquesta esloveno, Anton Nanut, quien vio una obra mía en una comisión de examen y decidió grabarla con la [Orquesta] Sinfónica Eslovena. Después ahí me tocaron varias obras y, finalmente, en el medio esloveno ya me había logrado instalar. Estaba bastante contento porque me consideraban, pero igual tenía la inquietud que tenían todas las personas del Este, que era pasar al otro lado de Europa. Capaz que fuera una realidad idealizada...

Entonces decidí irme a Viena, Austria, donde estuve cuatro años. Estudié con el profesor Heinrich Gattermeyer, pero la verdad es que no lo necesitaba tanto. Era una persona muy agradable, conversábamos, pero no fue la causa principal por la que yo quería seguir estudiando. Lo principal era que, llegando a Viena -estamos hablando de la época preinternet-me encontré con una inmensa biblioteca donde yo podía ver cualquier partitura, donde había todo tipo de discos, muchísimos conciertos... Me encontré con muchos ensambles de música contemporánea, festivales, y la verdad, lo que yo aprendí en Viena tiene más que ver con eso. Y lo segundo lo aprendí con el profesor Peter Burwik, director con el que tomé el primer curso de dirección de ensamble de música contemporánea. Estudié varios años con él en la universidad y después en forma particular. Era algo que me faltaba en mi formación. De hecho, en Eslovenia había estudiado solamente dirección coral. Para un compositor estar vinculado a la dirección implica involucrarse con la interpretación, lo que es muy importante. Digo esto porque antes, históricamente, todos sabemos que los compositores dirigían sus obras; incluso las interpretaban como instrumentistas, lo que hoy se ha perdido. Entonces, claro, eso fue la otra cosa que yo pude aprovechar estando en Viena.

Después de concluir mis estudios, por razones casi casuales terminé viniéndome a Chile, que me era un lugar prácticamente desconocido. Ni siquiera sabía que existían la Universidad de Chile y la Universidad Católica, pero de alguna manera esta experiencia resultó ser interesante para mí... y así me quedé acá.

PA: Bueno, en mi caso hay puntos comunes con Alejandro, porque tuvimos el mismo maestro en composición: Cirilo Vila. Eso sí, yo estudié Pedagogía en Música primero y ahí comencé a componer piezas en el ramo de Composición Escolar que dictaba Santiago Vera, obviamente siguiendo una orientación referida a la pedagogía. En Pedagogía habían buenos músicos, la mayoría vinculados a la música popular, de tal manera que yo compuse música sin preguntarme si lo que hacía era popular, docto o contemporáneo. Lo que a mí me interesaba era el sonido en sí. 
Tuve por compañero a Jaime Vivanco, un gran músico, lamentablemente fallecido y que en ese entonces era el tecladista del grupo musical Fulano, grupo muy conocido en los años ochenta. Fuera de los horarios de clases nos juntábamos con él y otros compañeros a escuchar música. Su padre viajaba por trabajo a Estados Unidos y, por medio de él, Jaime encargaba discos de toda clase de música, incluidos algunos de Stockhausen. Y entre esas audiciones que hicimos -con un grupo de amigos de Pedagogíaescuché Stimmung de Stockhausen, y desde ahí quedé muy interesado en esa música contemporánea.

Lo primero que quise saber es ¡cómo se escribía esa música! y fue esa inquietud básica la que me llevó a preguntarme respecto de la composición, y a preguntarme si "componer" se podía estudiar. Conseguí una reunión con el profesor Juan Lémann de la Facultad de Artes de la Universidad de Chile. Le llevé, en esa época, casetes con música que yo había compuesto y fue él que me dijo: "tú debieras estudiar composición”. Yo tenía obviamente la experiencia de pedagogía, había estudiado los ramos clásicos como armonía, análisis, un poco de contrapunto, pero no composición. Y así, en paralelo a mis estudios de pedagogía, Juan Lémann me tomó como alumno.

Las clases con Lémann eran de alguna manera particulares, porque la carrera de composición no estaba abierta oficialmente. Él veía mis trabajos y me hacía comentarios y sobre todo escuchábamos música que él llevaba, hasta que finalmente entré a la carrera de composición como alumno regular. Lémann fue mi primer profesor de composición, de contrapunto y orquestación. Al cabo de poco tiempo, desgraciadamente se enfermó y tuvo que ausentarse de la Facultad [de Artes]. Entonces él habló con Cirilo [Vila], quien me tomó como alumno... Y a propósito de que está aquí, a mi lado, Eduardo Cáceres, recuerdo que en esa época, los 80, fui a los Festivales de la Agrupación Musical Anacrusa, que se hicieron en el [Instituto] Goethe y allí escuché por primera vez música contemporánea "en vivo", lo que me motivó mucho más en mis estudios. Y respecto de las clases con Cirilo, así como lo decía Alejandro, él "no enseñaba”..., cómo decirlo, no daba claves...

GM: ¿No daba recetas?

PA: Así es, no daba recetas. Yo le llevaba mis incipientes partituras, a modo de balbuceo, tratando de definir lo que eran mis ideas, y Cirilo lo que hacía era relacionarlas con otras músicas. En ese tiempo tener partituras de otros compositores no era fácil, no como ahora que uno puede tener acceso y puede bajar de internet mucho material... Y las pocas que había se prestaban por poco tiempo. Además no había un staff de partituras de música contemporánea que las que uno pudiera necesitar o elegir. Yo incluso copié a mano varias partituras porque tampoco se podían sacar fotocopias como ahora. Así es que en este sentido fui muy autodidacta...

En mi época de estudio conocí al compositor Andrés Alcalde, y de él se tocó en Anacrusa una pieza para cello solo, Der Mondbach, que la interpretó Edgar Fischer. Recuerdo que al escuchar su pieza me "volví loco" y me dije: "quiero conocer al compositor que hizo esta pieza". Finalmente, conversando entre Alcalde, Cirilo y yo, llegamos al acuerdo en que mis estudios con Cirilo serían sobre todo en los ramos de análisis y armonía, y trabajaría paralelamente con Alcalde, estudiando con él composición, de manera particular.

La verdad es que yo estoy muy agradecido de Cirilo, sobre todo por lo que él me entregó en el ramo de análisis, porque ahí me hizo conocer música que yo desconocía. Y digo conocer en el sentido amplio de la palabra, porque él tocaba en el piano todas las piezas que analizaba. En su clase no solo se analizaba, por ejemplo una sonata de Beethoven, sino que también se escuchaba tocada al piano por Cirilo. Además se tenían conversaciones muy bonitas con él. Yo salía de las clases de análisis con tanta energía como de las clases de composición, pues Cirilo me problematizaba diciendo: "aquí, en esta sección hay un problema”... Y, si se recuerdan quienes fuimos sus alumnos, él dibujaba un pequeño "anteojito" que significaba que allí había que revisar. No entregaba soluciones sino que seleccionaba secciones de mi pieza y las comparaba con algún compositor (clásico). Yo aprendía mucho de eso. Cirilo era un maestro muy culto. Después de sus clases venía el trabajo solo: escuchar música, mirar partituras, componer, analizar. Con Andrés Alcalde, en cambio, era un trabajo detallista, un muy buen complemento para mí, un trabajo fino, de largas conversaciones. Así que fue muy enriquecedor tener acceso a esos dos mundos. La complementación la hice yo mismo, obviamente años después.

En realidad, creo que "partí tarde" en la composición, pero seguí adelante en la Facultad y, al finalizar mis estudios, tuve la suerte de ganarme la beca alemana DAAD. La comisión en Chile que me dio la beca -y que me advirtió que tenía pocas posibilidades de ganármela, porque estaba al límite del plazo por la edad- la formaban el maestro [Gustavo] Becerra, que entonces se encontraba de visita en 
Chile, y Federico Heinlein. Yo postulé para estudiar con el compositor Helmut Lachenmann. Recuerdo que ante la comisión alemana llegaron tres postulantes chilenos y yo iba en el tercer lugar. Eran dos intérpretes primero y yo al final, y supe que Lachenmann dijo: "siempre traemos instrumentistas, así que ¿por qué no invertimos el orden y dejamos al compositor primero?”... Tuve mucha suerte.

Lachenmann no tenía cupo para extranjeros ese semestre, así es que me tomó el compositor Johannes Fritsch, que estaba también en la comisión. Johannes Fritsch había sido el violista del ensamble de Stockhausen y profesor en la Escuela Superior de Música de Colonia. Tuve suerte que me tomara él, pues Johannes era parecido a Cirilo. Era muy afable y me brindó un amplio espacio para reflexionar. Sus clases eran una vez a la semana y duraban todo el día. Yo arrendaba un departamento en Colonia, muy cerca de la Kölner Musikhochschule, así es que me iba caminando a la Escuela. Las clases partían a las nueve de la mañana y participaban además intérpretes y exalumnos de él... Almorzábamos todos juntos, íbamos siempre al casino o a otro lugar cerca y después, en la tarde, seguíamos las clases. Me acuerdo perfectamente: era la sala número 18, en el segundo piso de la Musikhochschule de Colonia. La sala tenía dos pianos de cola y un estante equipado para grabar y escuchar música. De los tres años que estuve en Colonia, pasé mucho tiempo en esa sala.

Por otra parte, recordando el trabajo realizado con Andrés Alcalde, que me había dejado muy interesado en tener conciencia del pensamiento que se genera al componer música -no me refiero a una fórmula, sino al trabajo inventivo que se genera a partir de "la nada" -, ello me motivó a que al final de uno de los semestres en Colonia, optara por irme a Siena (Italia) a hacer un curso con [Franco] Donatoni, que duraba más o menos dos meses. Me fue bastante bien y seleccionaron una obra mía que se tocó en el concierto final. También durante mi estadía en Alemania participé en algunos cursos de composición en Darmstadt y tomé clases con los compositores Brian Ferneyhough, Helmut Lachenmann y Mathias Spahlinger. Cada uno de ellos me dejó una huella distinta. Hice lo que haría un estudiante de composición de acá: mostrar una obra a cada uno de ellos y recibir opiniones muy distintas, y obviamente que eso era muy interesante.

Para terminar, puedo decir que todos los compositores con los que tuve clases se fijaron en aquello que a mí más me interesaba, y que fue lo que me llevó a estudiar composición: el sonido. Sí, tanto Franco Donatoni como Ferneyhough y Spahlinger, me hablaron mucho del material sonoro, y del detalle del sonido. Por otra parte, todos apuntaron a la brevedad de mis piezas, que era posible sostenerlas pues allí sucedían todas las cosas que suceden en una pieza de mayor extensión. Todos ellos me daban opiniones para no salirme de la brevedad. Ferneyhough me dijo que compusiera muchos trozos breves con la posibilidad de que formalmente posibilitaran un formato más grande. Aprendí mucho de estos profesores.

GM: Entre paréntesis, quisiera comentarles que todo el material musical de Cirilo Vila se encuentra acá, en el Archivo [de Música de la Biblioteca Nacional]: sus cuadernos de apuntes, sus estudios, partituras, libros, todo... Y esos "dibujos de ojitos o anteojos" de los que hablabas tú, Pablo, que él te hacía en tus partituras para recordarte los puntos que tenías que revisar y pensar, Cirilo también se los hacía a sí mismo en sus partituras, para llamarse la atención y revisar sus propios trabajos de composición.

EC: Bueno, la verdad es que yo a esta altura, después de escuchar los relatos de Alejandro y Pablo, estaría a punto de decir que habría que "canonizar" a Cirilo Vila, porque hemos sido todos una generación de discípulos del maestro Cirilo y, por ello, creo que le estamos eternamente agradecidos de su escuela. Sin embargo, el momento en el que yo llegué a él, y aquí voy a partir de cuando yo era "cabro chico"5... la verdad es que hay varias personas que yo diría que fueron para mí, no sé si maestros pero sí grandes profesores. En todo caso, para mí Cirilo fue como "el Maestro", así, con mayúscula.

Entonces, en realidad la formación que yo tuve fue muy diversa, en el sentido de la música. Cuando mis papás pensaron que tenía algunas condiciones musicales me pusieron en clases de guitarra, a los seis años, pero con músicos populares. De hecho estudié con Carlos Baeza, que no sé si alguien lo conocerá, pero él componía canciones, baladas, tenía un grupo que se llamaba Capablanca... Era música absolutamente baladista, popular; incluso él tenía distintos grupos. De ahí, con el tiempo, fui interesándome por el folclore y estudié con uno de los integrantes del grupo Los Cóndores. Hasta ese momento, la música que yo hacía era popular y, entremedio, también toqué guitarra eléctrica en un

5 Chilenismo que se refiere a un niño o preadolescente. 
grupo de rock - creo que eso le faltó decir a Alejandro6 - y considero que son parte de la formación de uno, que de alguna manera se van acumulando y van haciendo lo que uno finalmente llega a ser como compositor. Con el tiempo tuve una profesora de piano, Liliana Colzani, que me puso al día en la música de Tito Lederman, que era su marido, en donde conocí la llamada cocktail music. Este acercamiento a distintos tipos de música, en algún momento me llevó a vivir un tiempo -primero una temporada de tres meses y luego otra de igual duración-, en un pueblo del sur de Chile, Mininco concretamente, donde conocí emocionalmente la música mapuche. Yo creo que eso también me marcó mucho.

Con toda la experiencia anterior ingresé a estudiar pedagogía -de hecho fuimos compañeros con Pablo-y ahí paralelamente yo entré a estudiar percusión, donde tuve un profesor que me mostró mucha música, como fue Guillermo Rifo. Estudié percusión con él durante años, quien también tiene un panorama bastante amplio de la música, distintas miradas, cosa que para mí siempre fue importante y fundamental. Posteriormente, cuando entré a estudiar composición, lo hice directamente con Cirilo, porque era lo que yo quería. Yo dije "Cirilo o nadie". La verdad es que había otros profesores ahí7, pero para mí Cirilo era la única opción. Si no entraba con él, me iba para otro lado. Finalmente, Cirilo me tomó, hice la carrera que dura cinco años y seguí con él hasta que concluí con la última obra de titulación.

Entremedio también estuve en Alemania, y tomé clases con Gustavo Becerra, que entonces vivía en Oldenburg. Y la verdad es que a mí Becerra fue el que más me sedujo. También asistí a clases con Mauricio Kagel y Lachenmann, pero, igual, la verdad es que el que más me seducía era Becerra. De hecho yo me iba los fines de semana a su casa, compartía con su mujer y a veces con su familia, y en ocasiones me quedaba fines de semana completos allí. Entonces las sesiones eran muy extensas; hablábamos de todo. Yo diría que las relaciones con Becerra y Cirilo fueron de maestro-discípulo, pero también de amistad. Creo que a todos nos pasó que la relación que teníamos con el maestro era una relación además de los fines de semana; es decir, no solamente en las clases de la semana, sino en situaciones diferentes, casi familiares. Compartíamos mucho en encuentros extraacadémicos.

Adicionalmente, creo que mis experiencias frente a la diversidad, estando en Alemania, me llevaron, en alguna de mis vueltas -porque fui y volví dos veces, justamente a trabajar con Lachenmann-, a tener clases con un par de profesores interesados por la música para cine. Y estuve un tiempo trabajando con Michel Chion, que se ha dedicado mucho a la semiología desde el audiovisualismo, y también con Walter Schobert en Frankfurt, que igualmente ha trabajado mucho la música para cine. Entonces, de algún modo, yo diría que esta multiplicidad de visiones ha hecho que en general para mí la música -las músicas-, hayan pasado a ser "las músicas contemporáneas", en el sentido de las distintas visiones. De esta manera, he estado siempre muy interesado en el tema de la música que ha nacido de Latinoamérica, la música indigenista, y yo creo que todo esto me ha ayudado desde un comienzo a mi formación, a esta formación que yo diría que viene de variadas fuentes, tal como es el mundo de hoy: no hay una sola fuente desde donde uno puede beber.

Finalmente, creo que lo más importante de esto es poder lograr un proceso creativo de síntesis, de todo lo que uno ha recibido y no quedarse solamente con una sola línea, a menos que eso sea lo que a uno le interese. Pero de todas maneras, lograr el proceso de síntesis en la creación creo que es lo fundamental, por lo menos en lo que nos toca vivir actualmente. Eso por ahora, gracias.

GM: Bueno, para avanzar, si bien tengo muchas preguntas, voy a hacerles aquellas más generales porque lo importante es escucharlos a ustedes: ¿Cuál es entonces su forma de componer, qué metodología usan? ¿Hay una filosofía que la sustenta? ¿Qué heredaron de sus propios maestros que ahora ustedes aplican también en sus estudiantes? Y, como parte de su metodología de enseñanza, ¿cuál es la relación que establecen con sus estudiantes?

AG: Puedo responder algo en breve, porque en realidad yo cambio de método en cada obra. Lo aprendí de Cirilo, cuando ya me metí en el mundo de la libertad. Y eso aprovecho de decirlo aquí, pues el problema y desafío más complejo que puede enfrentar un ser humano es la libertad, así es que los dejo a ustedes pensando... Esto, porque efectivamente hoy se puede hacer cualquier cosa, lo que uno quiera, y a eso se le puede llamar composición o creación. Pero atendiendo a ello, justamente como

6 Alejandro Guarello también participó en grupos de rock antes de estudiar composición.

7 Se refiere al Departamento de Música de la Facultad de Artes de la Universidad de Chile. 
consejo de Cirilo, no olvido un lema maravilloso que existe en Occidente, que debe estar presente en la composición: "la unidad en la diversidad o la diversidad en la unidad". Esa es mi manera de reaccionar, de trabajar en particular cada obra acorde a los sonidos que la componen, intentando que cada pieza sea una analogía a un ente, a un organismo, donde las cosas se relacionan funcionalmente y, por tanto, de alguna manera, el hecho de por qué hay algo ahí, es porque a esa obra le pertenece, y no porque yo quiera. Y en ese sentido, recuerdo que desde el año 81/82, todavía siendo alumno de Cirilo -pero ya comenzando a interiorizarme-, casi todas mis obras tienen que ver con un diálogo entre lo que a mí se me ocurrió, lo que yo escribí y lo que voy a escribir. Entonces lo que voy a escribir no es prerrogativa mía solamente, sino que también es prerrogativa de lo que ya escribí, pues allí se produce una interacción, una suerte de diálogo que también influye en la creación. Y así, sucesivamente, se van creando las obras.

\section{GM: ¿Pero cómo lo enseñas tú a tus estudiantes?}

AG: Noooo... Mi respuesta es: no lo enseño. Yo creo que no teniendo las herramientas, las virtudes de un Cirilo Vila, sería imposible reproducir esa manera, y a los alumnos que he tenido, en general, primero les he propuesto el problema de la libertad; segundo, tomar conciencia de que ellos están escribiendo para alguien, para un ser humano, y que lo que construyen debe tener relación y ser profundamente meditado, una decisión pensada y, por tanto, lo que decidan que lo decidan con propiedad. Y la libertad es absoluta... En realidad yo practico más bien el entusiasmo por la composición, de transmitir el entusiasmo, de transmitir la problemática. Hay algunos que se interesan y otros que abandonan, pero en general intento, más que enseñar, motivar, apoyar a que busquen soluciones ellos mismos al problema que se les presenta.

AS: No creo que exista una metodología previa a la obra, yo creo que el método surge en el proceso. Creo que hay una idea básica, no sé... no tengo muy claro cómo uno empieza a componer. Es un proceso bastante caótico en un comienzo, ¿cómo se llega de cero a algo?, no es explicable... Es una paradoja. Hay algo, una sensación que se traduce en alguna idea un poco vaga y que de a poco se va cada vez poniendo más clara, y a partir de ese punto yo creo que uno puede buscar sistematizar algo. Y creo que eso no es tan distinto de la manera a cómo uno trabaja con un alumno. Primero, tengo que entender qué hay ahí, y una vez que hay un material, trato de ver cuál es la potencialidad que tiene, cómo se puede cambiar, cómo se puede conducir, cómo se puede variar. Y entonces el método va a tener que ver con eso, con esa idea de que del mismo material, de la idea más básica, más primaria, recién puede aparecer una idea de cómo estructurarla. Yo creo que eso es igual para mí como para el alumno.

Respecto de la "filosofía" que sustenta a mi música, una de las cosas que planteo, firmemente, es que no todo es posible. En términos de libertad uno sí puede hacer cualquier cosa, pero yo creo que los límites están en nuestro funcionamiento perceptivo. Podríamos decir que si tuviéramos mejor memoria, la música tendría menos repeticiones, y al revés, si tuviéramos peor memoria la música tendría más repeticiones. La música fue construida no solamente de premisas estéticas o prejuicios de la época, sino también desde la naturaleza, de la capacidad perceptiva que tiene el ser humano. Yo creo que esos son límites reales que se tienen que respetar, pues no todo es posible. Hoy, tener la idea de que hay algo sí es un límite... Yo creo que ello es muy deseable, debido a que todos queremos tener un límite, pero obviamente que en un mar de posibilidades es muy difícil manejarse. Uno necesita acotar. Yo diría que, en síntesis, esa es un poco mi filosofía: partir de cómo funciona nuestra percepción, cómo funciona nuestra visión, cómo funciona nuestra atención... o sea, nuestra atención no es un acto voluntario. Muchas veces uno estudiaba algo en el colegio y a pesar del esfuerzo no podía memorizar, simplemente no entraba. Hay muchas otras cosas que quisiéramos olvidar y no podemos olvidar, se graban y quedan; esos son mecanismos autónomos. Si uno desde la empatía puede llegar a acercarse a eso, imaginarse qué se puede entender, qué se puede escuchar, cómo podría llegar a transmitirse a alguien que está afuera escuchando la obra, esa es parte de mi filosofía.

PA: Yo partí componiendo la pieza que sería oficialmente la primera: Ilógica, para guitarra. Parece que esa pieza funciona bien pues todavía hay alumnos de guitarra que la tocan en su repertorio de estudio. He mantenido una cuestión muy espontánea respecto de la composición, que es preocuparme del instrumento para el que compongo: ver qué posibilidades tiene e inmediatamente escribir. Así no me alejo de lo espontáneo. Gradualmente uno va recurriendo a cosas que va incorporando. Hay 
un diálogo entre lo que escribo espontáneamente y una natural problematización y ahí justifico la escritura. Porque en realidad uno podría hacer música sin escribirla, pero sería más lento contarle al intérprete o hablar con el intérprete acerca de lo que uno quiere hacer y cómo hacerlo.

Yo pasé por una etapa en que escribía espontáneamente, sin siquiera escuchar lo que estaba escribiendo. Me dejé llevar por el dibujo y relaciones gráficas de lo que iba sucediendo. Después me di cuenta que el dibujo gráfico podía derivar en una sistematización. La escritura me brinda la posibilidad de dialogar, de distanciarme de la idea básica y hacer el record play. Creo que es una práctica que he mantenido... cómo construir la forma del material, qué forma puede tener. Sobre todo cuestiones simples: si se puede avanzar, si se puede ralentar mucho o poco, si se da la posibilidad de repetirse o reiterarse, y también la relación de ese material con el auditor... Si bien es imposible que me ponga en la cabeza de 30 o 100 personas que van a escuchar la obra, sí debo ser el primer auditor de mí mismo y decidir si efectivamente lo que estoy escribiendo... corresponde a una poética y si lo que está ahí estructurado tiene un sentido real en el sonido. Esto para mí es clave. Sobre todo ahora que dirijo un ensamble hace más de diez años. La relación con los intérpretes me ha ayudado muchísimo en la escritura, en todo sentido.

Y respecto de los alumnos, yo he pasado por varias etapas con ellos. Tuve alumnos con los que convivíamos muy de cerca; el problema de uno lo resolvíamos todos. Disfruté mucho esa etapa con Francisco Silva, Andrés Núñez, Daniel Osorio, Juan Pablo Orrego (los últimos dos hoy en Alemania) y Antonio Carvallo. Fue una etapa de mucho trabajo en conjunto, en la composición. Es importante meterse en la problemática de lo que el alumno trae. Los que son alumnos míos saben que me preocupo mucho de que cada uno tenga conciencia de su material, de qué hay ahí, de las conjunciones sonoras que están ahí, de cosas muy simples y otras complejas. Por ahora -y en una primera instancia- no me interesa mucho que el alumno me explique cómo llegó a lo que me trae en su partitura, pero sí que tenga conciencia de lo que allí tiene. Si el alumno necesita que yo participe de su proceso, lo hago. Hay alumnos que construyen procesos súper interesantes, pero que en la práctica no funcionan. Me preocupan cosas muy concretas, insisto. Hay mil maneras de partir una obra pero no hay mil maneras de continuarla y menos aún de terminarla, porque el material empieza a acotar el desarrollo de un proceso. Otra cosa que les digo a ellos, es que no escriban nada que no puedan imaginarse tocar, cantar o reproducir. No sé si los alumnos me hacen caso. Y hay una palabra que puede ser medio cliché pero es importante: ser auténtico. Trato de que el alumno sea lo más auténtico y acorde a lo que es. Yo me intereso en guiar a alumnos con un planteamiento teórico, abstracto o complejo. He tenido alumnos que lo han hecho, pero cuando noto que los procesos complejos son una suerte de máscara y que encubren soluciones simples, soy muy duro y franco y les digo: "estás estructurando algo de lo que tú mismo no tienes conciencia”. Eso es lo que intento transmitir, pero no enseñar.

EC: Finalmente yo creo que la diversidad ha sido una característica que de alguna manera nos ha distinguido en este mundo chileno, y son tan valiosas unas posturas como las otras. Creo que lo que no funciona bien, es cuando uno piensa que los demás tienen que componer como compone uno. Yo creo que las distintas líneas que hay en la composición y, finalmente, que han derivado también en la educación, han sido producto de las experiencias que cada uno ha tenido en su vida personal y también en su formación. En mi caso, para componer siempre ha sido muy importante la improvisación. Pensando en algún momento en los modelos, por ejemplo partiendo de compositores del barroco..., o el mismo Mozart, después Beethoven, qué sé yo, eran todos grandes improvisadores. En general, creo que ellos de alguna manera nos demostraron que hacer la música, o sea, tocarla con el instrumento, es fundamental. Eso se fue perdiendo con el tiempo, el hecho de improvisar fue derivando en ir armando la música de una manera más intelectual, que no tenía un acercamiento directamente con el instrumento... Pero para mí, fundamentalmente los timbres siempre han sido una gran preocupación. De hecho, el color, el timbre es lo que me cautiva, es lo primero que me cautiva.

Mi método de componer, por decirlo así, es que yo voy armando improvisaciones en mi cabeza y puede pasar mucho tiempo en que no escriba nada y, sin embargo, estoy armando la obra y al otro día sigo haciéndola. Felizmente la memoria me acompaña todavía, en donde voy armando una obra y en algún momento cuando siento que está lista, ahí recién la escribo, por eso me demoro muy poco en escribir, pero he estado un largo tiempo armándola en mi cabeza. Es un sistema que finalmente me ha acomodado. En ese sentido, siento que cada obra es única en sí misma, va por caminos distintos, pero independientemente de eso, en mi caso yo también tengo reciclaje de material. Hay material que ocupo de otras obras y eso encuentro que es completamente legítimo 
porque, por último, la "propiedad intelectual" a mí no me podría decir nada porque estrictamente son obras mías, estoy haciendo reciclaje de mí mismo, de motivos que finalmente a mí me seducen o me han seducido en algún momento. En general, creo que he tenido la fortaleza interna de componer lo que se me ocurre, no necesariamente siguiendo una línea estética predeterminada, sino que he podido trabajar con distintas situaciones de la música que no necesariamente están asociadas a una línea de la música contemporánea que se supone que debiera ser. Y eso lo hice así desde muy temprano. Si se me ocurre trabajar con guitarra eléctrica y bajo también lo hago, de hecho tengo una obra para doce guitarras eléctricas y cuatro bajos, y tal vez no están dentro de la línea de la música contemporánea, pero es lo que me nació en un momento y eso es lo que compuse. De hecho hasta hoy lo sigo haciendo.

Ahora, cómo se traspasa esto a los estudiantes... yo creo que es complejo porque siempre he tratado de separar por un lado lo que yo hago, de lo que trae el estudiante. Yo digo que el estudiante en general es todo un mundo que merece ser respetado. Por lo menos es lo que yo trato de hacer siempre. Entonces para acercarme a él -y esto puede sonar como medio extraño-, yo primero hago un estudio, por decirlo así, psicológico del estudiante. Es decir, me interesa saber de dónde viene, qué quiere, cuáles son sus inquietudes, de qué se tiene que desprender, cuáles son sus "fantasmas". Porque normalmente el estudiante que tiene estudios previos, por ejemplo en el Conservatorio, qué sé yo, tiene una serie de "fantasmas" dentro de lo que es la composición musical. Hay varios mitos y tabúes de los que hay que de alguna manera despojarse. Yo creo que ahí hay un trabajo psicológico que tiene que hacer el profesor respecto de despejar, de limpiar y tratar de llegar lo más posible a la esencia del estudiante, de lo que quiere, y de ahí soltarlo y darle libertad, que es una palabra que no sabría cómo definir pero que cada uno tiene que sentir que lo que está haciendo, lo está haciendo completamente libre y no componiendo ni para el profesor ni para nadie.

Lo anterior, sin embargo, es una situación compleja obviamente, porque cuando uno compone para alguien en especial, también se producen algunas problemáticas. Por ejemplo, en mi caso, siempre trato de no desvincularme de mi situación social. Para mí, la composición está inserta en un medio social, en una situación sociopolítica que para mí es fundamental; no puedo desvincularme de eso. Pero no está dirigida hacia un ser especial, sino más bien a una situación; entonces esa vinculación para mí es fundamental porque siempre creo que los compositores han estado muy ligados a sus situaciones, a sus momentos. Si uno estudia la música de Debussy, por ejemplo, el mismo Beethoven o Stockhausen, se da cuenta de que estos compositores siempre tuvieron una vinculación con su medio, con lo que está sucediendo, diez años antes, veinte años antes, treinta años después. Yo creo que de eso no hay que desprenderse nunca, y eso a mí me tiene siempre cautivo.

Ahora, claro que aquí hay una paradoja, por ejemplo cuando uno toma a un estudiante desde los primeros pasos. Escuchaba antes al maestro Juan Allende-Blin, que hablaba de cómo enseñaba la composición y yo pensaba que, dentro de los elementos fundamentales que él mencionaba, para mí es el ritmo (porque él hablaba de la melodía). Para mí el vínculo que tiene el ritmo en la enseñanza de la composición es fundamental, sobre todo en un continente como el nuestro, que es riquísimo en ritmos. Y creo que entregar valores por medio del ritmo y de lo que tenemos a nuestro alrededor -de lo que ha sido la conformación de nuestras culturas en Latinoamérica-, van por el lado fundamentalmente del ritmo. Eso nos llega mucho más de lo que creemos, lo tenemos mucho más internalizado de lo que podemos aceptar intelectualmente. Es algo que tenemos muy emocionalmente y que a veces no se acepta. En ese sentido, creo que la enseñanza del ritmo -para mí por lo menos- ha sido siempre una cuestión fundamental dentro de la enseñanza de la composición, no tanto la melodía, porque la melodía me lleva a otros campos e, incluso, cuando el maestro Allende hablaba de los conceptos melódicos, partiendo del contrapunto y todo esto, la verdad es que yo pienso en los ritmos ancestrales, pienso en los ritmos milenarios. Entonces yo creo que descubrir eso, o ir en su búsqueda, nos acerca más a lo que podríamos llegar a ser, o lo que somos.

GM: Muchas gracias... esto está muy interesante y tengo varias preguntas más al respecto, pero creo que no vamos a alcanzar con todas. Entonces les pido mejor pasar a un "segundo movimiento" de la conversación. Lo primero, considerando que el contexto ha cambiado muchísimo, las escuelas de música hoy no son lo mismo que antes, la realidad social y económica es diferente, las exigencias, las políticas, etc., todo ha ido cambiando. Entonces las preguntas que me surgen son: ¿Existe hoy la relación de "maestro-discípulo”? ¿Existe la figura del taller o más bien estamos en la figura de la "clase universitaria", "académica", de una relación basada en el "profesor-alumno" o "alumnos"? 
AG: Ya, brevemente. Yo creo que coexisten todo tipo de formas. A veces incluso en la [Universidad] Católica comenzamos con un colectivo y luego se va derivando hacia una situación personal y también, por ejemplo, se da la posibilidad de cambiar de profesor cada cierto tiempo, que es una manera de "vitrinear" y de experimentar diferentes situaciones. Y por supuesto que la política o práctica de un taller es muy interesante... ¿Cuál es el beneficio del taller? Que un alumno ve en otro alumno problemas que no pensaba, pero que le empiezan a interesar. Entonces, ese compartir problemáticas funciona muy bien en el taller y la situación maestro-discípulo, que también se da, sigue siendo vigente, posible y provechosa. Pero todo esto es válido, en la medida en que -vuelvo a insistir- el maestro no le imponga lo que tiene que hacer al alumno. Eso ya es otra cosa.

AS: Yo creo también que es una responsabilidad personal, porque uno finalmente tiene un alumno que estudia composición con un profesor y es un alumno que tiene una clase individual. Puede ser que el término "maestro" sea un poco anacrónico, pero es una responsabilidad personal, y esa responsabilidad tiene que ver con muchos aspectos técnicos que el alumno realmente necesita asimilar, para ello alguien tiene que guiarlo. Solo conocer los instrumentos ya es mucho. Saber qué se puede hacer con un violín, una flauta, un clarinete, cómo se pueden combinar. Y creo que el profesor, llámese "maestro" o guía, desarrolla un vínculo muy personal con el alumno. Yo creo que eso es necesario por la complejidad del oficio.

AG: Me gustaría agregar una cosa que no hemos hablado de la composición, ya que Aliocha está tomando un tema que es muy distinto, que son las herramientas. O sea, la enseñanza de la orquestación, de la organología, del solfeo. Por supuesto que es fundamental y tiene que ser al detalle, de tal manera que el alumno, si está escribiendo un armónico, sepa perfectamente qué nota está sonando, y eso no tiene que ver con la creación, sino con las herramientas de la praxis, de la escritura musical... Es importante dividir estos aspectos.

GM: De acuerdo, después vamos a hablar más acerca de ello...

PA: Yo a veces me siento más resolviendo ese tipo de cosas en una clase de composición, y no es que sean menos importantes. Ya dije que, justamente, respecto de la problemática, el alumno debe saber escribir como parte de su inventiva... Y de la conexión creativa que se pueda dar con un grupo de alumnos, cuando sucede puede llegar a ser muy hermosa, muy interesante para ambos, muy rica, porque en realidad cuando uno está en la parte creativa, el espacio que se abre ahí no tiene dueño, cualquiera puede dar una idea que le sirva a la obra. Pero normalmente... me siento más bien para resolver problemas concretos.

EC: Sí, yo creo que hay un conflicto acá a partir de tus preguntas, porque de alguna manera la educación musical ha ido adquiriendo un ribete de generalidad, en donde antiguamente habían más particularidades, relación que yo creo se ha ido perdiendo; es decir, creo que la educación básica de música, actualmente está más bien confundida en esta relación antigua de maestro-discípulo. Yo estoy sintiendo que en la educación básica de la música estamos en una especie de mar sin individualidades. Sin embargo, yo estoy teniendo una experiencia muy bonita, pues siento que existe la relación maestro-discípulo en el programa de Magíster. Allí tengo varios alumnos en donde siento que se va produciendo, por el mismo nivel del estudiante, que trae una experiencia mayor, un grado también de interés, una capacidad y conocimiento mayores, además, yo diría, conducido y elegido por sí mismo. Allí creo que se pueden lograr estas relaciones de maestro-discípulo mucho más intensamente. Por lo menos a mí me está pasando eso, más que en la formación básica y en la formación intermedia.

GM: Volviendo un poco a lo que decía Alejandro, en cuanto a las técnicas, a las herramientas, acá en Chile -lo conversamos con Luis Merino- se han observado en la tradición dos tendencias muy claras: una de Julio Perceval, que insistía mucho en el oficio, en aprender orquestación, contrapunto, armonía, etc. y otra -de Becerra- que decía “componga, componga, haga creación”.... Tal vez esto se está planteando en forma un poco polarizada, pero para entendernos sería interesante ver cómo creen ustedes que debe enseñarse la composición en cuanto a la técnica por un lado y la creación por otra y, además, ver hasta qué punto la academia ayuda o complica la formación en el sentido de que hay 
programas que a veces son muy rígidos. Entonces ¿qué pasa con los programas respecto del "profesor académico" y su forma de enseñar?

AG: Bueno, el enfoque de Perceval se debe a su formación de organista. El organista es un hombre de oficio y se entiende perfectamente su postura. Por otro lado, en relación con Becerra, él es un creador, con el "bicho adentro" comiéndole segundo a segundo sus inquietudes, metiéndose en veinte mil problemas, no solamente musicales sino que semiológicos, históricos, etc., y también ello justifica su postura. A lo que yo me refería antes, a la cosa técnica, dividiendo el fenómeno creativo propiamente tal del discurso musical, es respecto de las herramientas. Con las herramientas me refiero a que el alumno sepa, y es importante, por qué la armonía que se enseña es así; por qué el contrapunto que se aprende y se enseña es así. Por qué la orquestación es así... Aquí hay un punto interesante, porque efectivamente hoy la orquestación excede a los tratados y los compendios y, por tanto, hay que investigar más de los instrumentos, hay que meterse en la problemática y recursos extendidos de los instrumentos.

Además, se incorporó en un momento dado, aprovechando que no hemos hablado de eso, todo el fenómeno electroacústico, electrónico de los software, de inventar software, etc. Esto tiene que ver con herramientas, porque si bien puedes ser un genio en el manejo de las máquinas igual tienes que crear, y esa es otra problemática. Entonces, todas las herramientas que permiten la escritura por un lado, o la factura electrónica por otro, ese es un asunto que el académico puede dar perfectamente, pero el aspecto creativo, eso es a lo que yo me refería un poquito drásticamente al comienzo: cómo enfrentar la libertad, por ejemplo, es algo que "rebasa" a la academia. Yo creo que uno tiene que tratar de motivar la inquietud en el alumno, de tal manera que con los años, de la vida, vaya encontrando esa cuestión, que no se logra tanto ni con la licenciatura, ni con el magíster; ni en esa cosa tan estricta que es la academia. El aspecto creativo se logra, como dice Becerra "escribe y escribe", pero a la vez "escribe y reflexiona", y eso es una cosa que viene con la edad, con la madurez, con la experiencia. Y con el autoaprendizaje, cuando notas que ya no necesitas la opinión de los demás. Es muy típico, no sé si les ha pasado, que de repente aparece un alumno de hace cuatro años y viene a uno y le dice: "sabe, le quiero mostrar esto, a ver qué me dice"... Uno se da cuenta de que ese alumno todavía no tiene vuelo propio, no se cree el cuento, no se cree que las decisiones que tomó son las que había que tomar. Entonces busca apoyo, busca opiniones. Eso es típico de alguien que todavía no vuela solo. Pero en realidad el aspecto creativo es algo que viene con el tiempo, con la experiencia. Por eso, al principio de esta mesa yo decía que había que estimularlos, entusiasmarlos, porque el camino hay que recorrerlo solo.

GM: La libertad, ¿también parece que llega con el tiempo...?

AS: Bueno, yo podría partir refiriéndome a estas llamadas diferencias ideológicas... si necesita el alumno o no esta formación tradicional: cursos como contrapunto, armonía... Uno puede ver en la realidad que hay escuelas que tienen mucho o poco de este oficio tradicional, otras nada..., hay de todo. Yo pienso que acá no se trata de encontrar cuál es la ideología correcta, cuál es la mejor, sino cómo se practica esa ideología, y con qué nivel de profundidad y calidad se practica una ideología. Creo que muchas veces esto queda en segundo plano. De hecho me tocó concretamente ver que en muchas mallas el contrapunto desapareció. El contrapunto se terminó transformando en una disciplina inútil, pero por la manera como se practicaba. Durante mucho tiempo, por siglos, se mantuvo el método de "las especies" de J. J. Fux, que no tenía ninguna relación con ningún estilo, con ninguna música, era un ejercicio mecánico, donde el alumno decía que "si va una cuarta de paso, que la sexta acá, la nota no sé cuánto"... sin involucrar su musicalidad y sin haber ni el más mínimo proceso o experiencia creativa en el trabajo. Entonces, en la medida que uno asume el contrapunto como una experiencia creativa, en la medida que el alumno logra simultáneamente escuchar más de una voz, desarrollando la audición interna, sin duda que le va a servir, sea este un intérprete o compositor. Lamentablemente el contrapunto se enseñó mal por mucho tiempo y por eso se fue haciendo inútil. Entonces yo creo que no es importante decir cuál es la postura correcta, sino lo importante es ver cómo se lleva a cabo esa postura. Esa es mi opinión.

PA: Cuando llegué a Alemania me iba a los conciertos de las clases de instrumentos. Hoy en Chile los alumnos pueden hacerlo porque hay muchos conciertos. Pero como yo no vengo de la música clásica, en Colonia -el primer tiempo- traté de asistir a todos los conciertos de orquesta y los conciertos de 
cámara. Puedo decir que esta práctica puede llevarlo a uno a discriminar entre piezas bien escritas pero de poca creatividad. Hay algo que puede estar bien escrito, bien hecho, bien resuelto en términos técnicos, pero de poco vuelo creativo. Una vez, en un concierto de alumnos hubo coincidencia en discriminar y se dijo: "sí, esa obra es buena”. Después en la clase se comentó si podríamos definir "y explicar” por qué todos decíamos que esa obra era buena. Creo que sí puede ser que el alumno sea muy eficaz, que sepa escribir una música bien resuelta pero no sé si eso es todo. La creatividad para mí tiene que ver con el riesgo, con la experimentación con uno mismo, incluso con el fracaso. Hay cosas que en realidad no funcionan la primera vez. Cuando digo creatividad me refiero a "lo particular", de lo particular que cada obra tiene. Sí, siempre hay algo particular pero también cosas generales y comunes. Yo creo que ahí, cuando uno logra diferenciar estas dos cuestiones, puede sentir que está haciendo música bien hecha -esto puede sonar muy académico-, pero además particular, en su sentido o aspecto creativo. Por ello separo estas dos cosas: la técnica de lo creativo.

EC: Es curioso porque con los años me doy cuenta que tenemos bastantes más cosas en común entre nosotros aquí presentes. Sin embargo pareciera ser que no. Y estoy comprobando, en realidad, estas cosas en común y me alegro. Felicito a los organizadores de esto, que de alguna manera nos convocan para darnos cuenta de lo que piensan los otros, nuestros colegas, con quienes no nos hemos comunicado durante mucho tiempo respecto de este tipo de cosas. Sin embargo, me alegra de que estemos sintiendo y trabajando en líneas tan similares...

Hay una situación que a mí me ha preocupado durante mucho tiempo, felizmente esto está desapareciendo, y es el engolosinamiento de las diferentes técnicas adheridas a distintos instrumentos, las famosas llamadas "técnicas extendidas", que en algún momento el estudiante quiere recoger y tener para sí mismo como si fueran una solución para la música contemporánea. Y la verdad es que este tipo de situaciones en algunos casos han pasado a ser tan postizas, que no reflejan nada de la creatividad pero sí mucho de conocimiento técnico. Eso se soluciona fácilmente con un poco de intelecto, eso está claro. Si uno tiene un poco de intelecto, puede aprender eso rápidamente y superponer o, como decía el maestro Kagel, "yuxtaponer" elementos y distintas técnicas y pareciera que con solo eso ya se tiene una composición hecha. Felizmente esto está desapareciendo porque hay unas generaciones muy jóvenes actualmente que están realizando un trabajo casi diría retro, como tratando de rescatar situaciones de la música de hace no sé cuánto tiempo. No estoy hablando de treinta años, eso es muy luego, sino que de hace más tiempo. Y eso también de alguna manera significa algo, en el sentido de que yo no sé si no hay más caminos para adelante o que el ser humano siempre está intentando volver a lo que hubo. Pero por lo menos el camino de las famosas "técnicas extendidas" es más amplio, pues para mí también se llaman multiculturales, porque hay muchas de ellas que vienen de hace dos mil años y parecieran ser nuevas, que las han practicado diferentes tipos de culturas y que en algún momento la música contemporánea se apropió de ellas. En todo caso, finalmente me pone muy contento que se estén desprendiendo de las "técnicas extendidas" según se entienden hoy, que lamentablemente fue casi como la característica del compositor joven durante varios años, por lo menos en Chile y, en general, en Latinoamérica.

GM: Ya nos queda poco tiempo, disculpen, entonces ahora les agradeceré que sus respuestas sean muy cortitas por favor... Revisando lo conversado, se ha hablado muy poco de la posición de cada uno de ustedes respecto del rol que cumple la improvisación y el análisis en la formación del músico. ¿Qué opinan al respecto?

AG: A ver, yo creo que el análisis es fundamental. El análisis entendido como intentar descubrir el cómo y por qué está hecha la música; así lo entiendo yo. Lo otro no sirve para nada, que esto es una forma sonata, que esta es la exposición... no, no sirve para nada. El análisis en el sentido de descubrir, eso sí sirve. El curso en la [Universidad] Católica se llama "Análisis de la composición musical”, no solo "Análisis". O sea, se trata de analizar por qué tal compositor hizo lo que hizo y en el contexto que lo hizo, y de alguna manera coincide con lo que hemos estado hablando.

La improvisación, yo creo que de alguna manera todos lo hacemos. De partida yo escucho muy poca música. De hecho, la gente que viene a mi casa dice "pero cómo, no tienes esto...”. No tengo discos. Llegó un momento en que yo funciono escuchando internamente y así uno está improvisando, uno está creando cosas, dándole vueltas, acordándose de cosas, cambiándolas, porque uno recuerda una parcialidad. Se entiende mucho la improvisación como la factura, en el sentido del jazz, yo toco, 
yo soy saxofonista, etc. O soy percusionista, soy esto, soy lo otro... La improvisación es neta... No hay tiempo para discutir esto, pero tiene que ver con la imaginación sonora. Pablo fue testigo, yo fui testigo presencial de Franco Donatoni, que improvisaba la escritura, y la escribía en tiempo real. O sea, en la pizarra y rápido, rapidísimo... Qué se yo, en cinco minutos llenaba la pizarra y la cuestión sonaba espectacular. ¿Por qué? Porque estaba dentro, él lo estaba sacando fuera y parecía una improvisación escrita pero en realidad la improvisación estuvo antes. Un poco Eduardo lo dijo: se puede tardar meses en una cuestión y luego se pasa en limpio. Y es cierto, no hay que entender la improvisación como la genérica, de estar ahí buscando en el piano, probando cosas. Hay mucha gente incluso que mete cosas al computador, no en términos electrónicos sino que en términos de que escribe cosas y las escucha y ahí decide si le gustó o no le gustó. Eso es fatal, es ridículo. Primero tiene que improvisar en su mente para tener la idea clara y después buscar, con la ayuda del profesor o con su propia experiencia, lograr escribirla o registrarla para que se comunique, en definitiva, la escritura con la realización de la música.

AS: Bueno, en la práctica la improvisación ya no se considera sistemáticamente en las mallas, solamente puede que la tengan los alumnos de música antigua, que tocan clavecín y a veces la necesitan... Pero yo creo que el problema se debe a que en gran parte los compositores ya no tienen formación instrumental. O sea, Beethoven podía improvisar porque tocaba mucho piano, era pianista, pero ahora, sin un dominio instrumental, la improvisación puede ser cualquier cosa, o sea, tirar cosas sobre un teclado... Eso ya son azares, no es improvisar para mí. Ver si algo resulta por casualidad. Entonces yo creo que la improvisación instrumental está ausente. No sé si es bueno o malo, pero no es tan fácil decir "pongamos un curso de improvisación" [en la malla curricular]. Yo creo que el problema tiene que ver con la realidad actual, de la separación del intérprete y el compositor, que ya es un hecho muy difícil de revertir.

Por otra parte, yo también creo que el análisis es muy importante. A mí me toca hacer clases de análisis con alumnos que son musicólogos, intérpretes, compositores y me interesa que les sirva en su quehacer. A veces yo veo que un método puede pasar de ser algo que ayuda a acercarse a la música para llegar a comprenderla mejor, a un fin en sí, de tal manera que la música termina estando al servicio del método. Yo trato siempre de llegar a algo práctico: si entendemos las relaciones internas en la música ¿qué implica eso para la interpretación?; si hay una cadencia ¿qué significa ello en términos de una estructura formal?... Es lo mismo que dije sobre el contrapunto. Si el análisis es solamente alimentar un método y usar la obra para alimentarlo, no serviría.

PA: Por mi parte creo que el análisis tiene que ver con buscar algo concreto en una obra: puede ser la polifonía, el ritmo, algo muy particular. El análisis tiene que ver directamente con el grado de entendimiento que uno tiene de la composición. Está claro que es recomendable estudiar las formas clásicas, pero si no se logra -como dicen Aliocha y Alejandro- que el análisis aporte a lo que uno hace en la composición, no tiene mucho sentido. En la Facultad [de Artes] de la Universidad [de Chile] el ramo de análisis trabaja las formas clásicas hasta comienzos del siglo XX. Pero un ramo que aborde el análisis de lo que sucede en la actualidad me parece que se está evaluando. En todo caso, el análisis solo sirve si tiene importancia en relación con lo que uno hace.

Y lo otro, respecto de la improvisación... sí, claro, en la práctica no existe. Pero hay una suerte de improvisación con el material que uno escribe. O sea, juzgar de una manera distinta las ideas, proyectar o probar distintas posibilidades de la escritura, puede ponernos individualmente en un estado de improvisación.

EC: Bueno, como pidió Gabriel respuestas cortas: creo que el análisis de la composición es fundamental. Y la improvisación en la composición también es fundamental.

GM: Gracias por sus respuestas, que igual dan para conversar bastante más, pero ya estamos terminando. Y vamos entonces a una última parte, aunque tengo muchas preguntas más que quisiera hacerles pero ya no alcanzamos... Ahora se trata de conversar sobre "música y contexto": ¿Qué pasa con la música y las otras artes, cómo se vinculan? ¿Cómo ustedes trabajan esa vinculación, si es que lo hacen, o solamente ustedes trabajan la música pura, desde adentro?

AG: Ya, respuesta corta porque en mi caso es demasiado claro: yo en realidad no trabajo fuera de la música y cuando lo he hecho ha sido por obligación, por encargo; por lo tanto, yo siempre he pensado 
en jugar el juego del sonido de la música con sus relaciones internas y eso es todo. Cirilo, por ejemplo, por el programa de la academia, me obligaba a escribir canciones.

\section{GM: ¿Con textos?}

AG: Sí, canciones con textos. Generalmente en la academia uno tiene que hacerlas, pero siempre por obligación. Nunca ha sido algo que yo diga: ¡ah, tal pintura o tal literatura o tal teatro! o tal..., lo que sea externo a mi música, no va conmigo. En mi caso es demasiado claro.

AS: Bueno, todos podemos observar, por ejemplo, que el público musical no coincide con lo que sería el público cultural. Uno ve gente que de repente sabe de literatura, sabe de pintura y de alguna manera tiene un bagaje cultural, y muchas veces en música llega hasta Wagner, eso es muy común. Pero por alguna razón el público musical quedó siendo un público exclusivo de la música... eso es una realidad. ¿Quién tiene la culpa de que sea así?, ¿debiera ser así? Ustedes pueden ver que, por ejemplo, la música antigua del cine de Hollywood era muy cercana a la música docta de la época; sin embargo eso ya no es así, de alguna manera la música contemporánea se ha ido alejando de otras expresiones culturales. En todo caso eso ya es otro tema, pero creo que hoy esa es la situación.

PA: Cirilo siempre decía que en algún momento era bueno para el compositor vincularse con el teatro, o con otras disciplinas. Yo creo que la ópera contemporánea existe. Yo mismo me interesé por lo escénico al conocer, por ejemplo, a Heiner Müller y Heiner Goebbels, siendo este último un compositor. Lo que más me interesó es que algunos de ellos llegaron a un nuevo concepto de lo que es una obra. Yo me he vinculado con lo escénico, que creo que sí puede ser algo enriquecedor. Pero si se llega desde la composición a otra disciplina, que entonces sea la música la que lleva a conectarse con esas otras disciplinas.

EC: En realidad yo creo que la contextualización por lo menos en mi caso se ha dado siempre. Yo he trabajado música para teatro, para cine, he hecho música para cortometrajes, música en vivo para exhibiciones también. He trabajado con chilenos, con textos de Neruda, con Nicanor Parra y Elicura Chihuailaf (texto en mapudungún). He trabajado con compañías de danza y me interesa esa contextualización. El año pasado estrené una ópera en Buenos Aires donde trabajé en conjunto con las otras disciplinas, incluido el maquillaje. Hasta ese punto he llegado, aparte de los textos y todo lo que eso conlleva. Para mí, en tales casos se trata de contextualizaciones necesarias.

GM: Bueno, respecto de ello ahora va otra vuelta de tuerca. A lo mejor algunos ya lo respondieron, pero igual les consulto acerca de la relación entre música y contexto sociocultural-político: ¿Alguno de ustedes se involucra o no con ello?

AG: A ver, acorde con mi respuesta anterior, como yo me involucro solo con el sonido, independientemente de mi pensamiento y de mis acciones en el campo político, social, etc., y además como pienso que la música no significa nada, entonces en mi caso es imposible. Y de hecho incluso si tú notas en los títulos de mis obras, podrían servir como lo hacía Nono para su compromiso, como miembro del $\mathrm{PCI}^{8}$, contextualizar con el título y la música era absolutamente abierta, pero en mi caso ni siquiera eso: definitivamente yo separo mi actividad; separo mi ser social de la creación musical.

AS: La música se crea en un contexto social. Si uno dijera que Beethoven escribía música para los ricos de su época, ¿por qué entonces en China hay veinte, o más millones de pianistas, que sin tener que ver con esta coyuntura original tocan sonatas de Beethoven? Me parece insuficiente tratar de ver o asociar la música al contexto social, económico o cultural en la que surgió. Por ejemplo, se podría decir que todos esos grandes castillos que uno admira, en realidad eran para el uso de los ricos que con plata de todo el mundo los construían, pero eso ¿de alguna manera restaría mérito a los arquitectos, ingenieros y artistas que trabajaron en ellos? Yo creo que la gracia del arte es justamente que va más allá de la coyuntura en la que se origina.

\footnotetext{
8 Partido Comunista Italiano.
} 
PA: Yo creo que declararse ser compositor ya es una acción política...

AG: Eso es cierto...

GM: Gracias, ¡clarísimas sus respuestas!

EC: Yo creo que el contexto social lo es todo. No hay ni buenos ni malos, simplemente el contexto social es todo, e involucrarse con ello en el momento en que uno existe, para mí es muy necesario.

GM: Finalmente, una última pregunta, cuyo tema ya se mencionó un poquito antes, se refiere a la tecnología. Sí, la tecnología ha avanzado muchísimo y está revolucionando todo, aclarando que, para ubicarnos bien en el tema, un violín también es tecnológico o un piano es una máquina muy compleja; sin embargo ahora estamos llegando al extremo de que hay robots o softwares que hacen composición..., lo que hablaba Alejandro un poco al principio. Entonces ¿qué pasa con la tecnología?, ¿qué pasa con la robotización y con el compositor? ¿Nos vamos a quedar cesantes? Lo digo un poco exageradamente, pero ¿cómo ven ustedes el fenómeno de la tecnología actual, los softwares, la programación? ¿Afecta ello a la composición y a los compositores?

AG: Yo estoy un poco lejos del asunto... Nunca hice mucha música electrónica y la he aplicado solamente en los softwares, pero tú te refieres a otra cosa, que es el eventual traslado de la responsabilidad creativa a un algoritmo, a un software o a una máquina. Ya estamos ad portas de la composición por parte de la inteligencia artificial y quizás esas máquinas logren -como decía Pablo- la eficiencia del uso de los recursos, pero la creatividad, no creo. Yo no creo que el compositor sea reemplazable.

AS: Yo creo que eso sería lo último que las máquinas reemplazarían, porque son procesos psicológicos tan complejos que si las máquinas llegaran a hacerlo todo, esto sería lo último que harían.

PA: Yo con la tecnología en realidad no me llevo. La verdad es que no me interesa mucho. He visto hartos compositores que juegan con el "juguetito nuevo", pero a mí personalmente no me interesa.

EC: A mí me interesa porque me preocupa. No puedo dar conclusiones, pero el tema no me es indiferente. Todavía no he llegado a ninguna conclusión respecto del uso de las nuevas tecnologías sonoras. De lo que sí me he dado cuenta, hasta el momento, es que hay mucha gente que las usa de una manera indiscriminada y fácil; es decir, hay un facilismo inherente a lo que entregan las soluciones tecnológicas, y por ahí va mi mayor preocupación.

GM: Bien, ya es hora de terminar y la verdad es que nos faltó tiempo, pero creo que hemos logrado tener una valiosa conversación, franca e interesante. ¡Muchas gracias a todos los compositores participantes y al público asistente! ${ }^{9}$

\section{ALGUNAS REFLEXIONES AL CIERRE DE ESTA EDICIÓN}

No caben dudas de que las opiniones vertidas por los cuatro compositores participantes en la mesa constituyen un valioso aporte para la mejor comprensión del estado actual de la enseñanza de la composición en Chile. Desde mi perspectiva, conociéndolos a todos ellos, les agradezco especialmente la honestidad y claridad con la que expresaron sus experiencias, pensamientos, enfoques y formas de enseñar la composición.

Dentro de lo expresado, llama la atención la clara presencia de Gustavo Becerra y Cirilo Vila como dos importantes referentes de la formación de compositores chilenos -ya instalados en nuestra

9 En seguida se ofreció la palabra para hacer breves preguntas o comentarios de los asistentes, que no se reproducen en esta ocasión por razones de espacio. El video completo de esta mesa de conversación, incluido el intercambio final, se puede consultar en el Archivo de Música de la Biblioteca Nacional. 
historia-, que se unen a Pedro Humberto Allende, entre otros. También llama la atención constatar que los cuatro compositores -Pablo Aranda, Eduardo Cáceres, Alejandro Guarello y Aliocha Solovera-, tienen posiciones estéticas y pedagógicas en ciertos aspectos coincidentes pero en otros completamente diferentes, lo que demuestra que las tendencias compositivas en Chile se han ido diversificando.

Finalmente, es importante agregar que al concluir la conversación se ofreció la palabra al público asistente y, entre otras inquietudes, se cuestionó la falta de una mujer en la mesa. Al respecto se puede decir que actualmente no existe en el país una mujer compositora que se dedique sistemáticamente a la enseñanza de la composición; no obstante, esto sin duda que está cambiando, pues ya se observa un creciente número de compositoras chilenas activas. Además se observa una nueva tendencia, que da cuenta del afloramiento de núcleos de compositores en diferentes ciudades que, junto a Santiago y a Valparaíso, incluye a La Serena, Valdivia y Viña del Mar, entre otras.

De esta manera, así como se diversifica la enseñanza de la composición en Chile, también se diversifica el repertorio de compositores/as chilenos/as activos/as, dentro y fuera del país. 